\title{
Third trimester placental volume and biometry measurement: A method-development study
}

DOI:

10.1016/j.placenta.2016.04.010

\section{Document Version}

Accepted author manuscript

Link to publication record in Manchester Research Explorer

\section{Citation for published version (APA):}

Higgins, L., Simcox, L., Sibley, C., Heazell, A., \& Johnstone, E. (2016). Third trimester placental volume and biometry measurement: A method-development study. Placenta, 42, 51-58.

https://doi.org/10.1016/j.placenta.2016.04.010

\section{Published in:}

Placenta

\section{Citing this paper}

Please note that where the full-text provided on Manchester Research Explorer is the Author Accepted Manuscript or Proof version this may differ from the final Published version. If citing, it is advised that you check and use the publisher's definitive version.

\section{General rights}

Copyright and moral rights for the publications made accessible in the Research Explorer are retained by the authors and/or other copyright owners and it is a condition of accessing publications that users recognise and abide by the legal requirements associated with these rights.

\section{Takedown policy}

If you believe that this document breaches copyright please refer to the University of Manchester's Takedown Procedures [http://man.ac.uk/04Y6Bo] or contact uml.scholarlycommunications@manchester.ac.uk providing relevant details, so we can investigate your claim.

\section{OPEN ACCESS}




\title{
Third trimester placental volume and biometry measurement: A method-development study
}

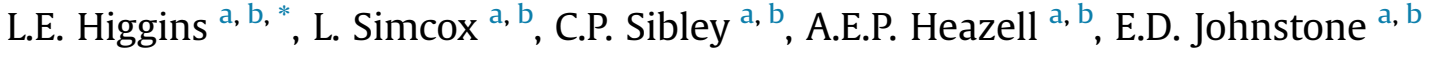 \\ a Maternal and Fetal Health Research Centre, Institute of Human Development, University of Manchester, United Kingdom \\ ${ }^{\mathrm{b}}$ St. Mary's Hospital, Central Manchester University Hospitals NHS Foundation Trust, Manchester Academic Health Science Centre, Manchester, M13 9WL, \\ United Kingdom
}

\section{A R T I C L E I N F O}

\section{Article history:}

Received 5 December 2015

Received in revised form 14 March 2016

Accepted 7 April 2016

\section{Keywords:}

Placental volume

Placental weight

Tissue density

Two-dimensional ultrasound

Three-dimensional ultrasound

VOCAL

Ellipse

\begin{abstract}
A B S T R A C T
Objectives: To test the hypothesis that third trimester placental biometry and volume can be measured by two-dimensional (2D) and three-dimensional (3D) ultrasound in utero, determining which method of measurement was most strongly correlated with true placental size ex vivo.

Methods: Singleton pregnancies underwent placental ultrasound within seven days of delivery $(\mathrm{n}=87$, $29^{+3}-41^{+5}$ weeks). Length and width (linear and curvilinear) and depth were estimated. Placental volume (PV) was estimated using $2 \mathrm{D}$ ellipse and shell techniques and $3 \mathrm{D}$ rotational $\left(15^{\circ}\right.$ and $30^{\circ}$ rotation angles) and multiplanar (5 and $10 \mathrm{~mm}$ slicing intervals) techniques. Measurements were compared to their true correlates following delivery. Intra- and inter-observer reliabilities of candidate placental size estimates were assessed by intraclass correlation coefficient (ICC).

Results: Curvilinear placental length $\left(\mathrm{R}_{\mathrm{s}}=0.24, \mathrm{p}=0.031\right)$, width $\left(\mathrm{R}_{\mathrm{S}}=0.27, \mathrm{p}=0.013\right)$ and depth $\left(\mathrm{R}_{\mathrm{s}}=0.31, \mathrm{p}=0.0056\right)$ correlated well with ex vivo measurements. All methods of PV estimation were related to ex vivo volume $\left(R_{s} \geq 0.32, p<0.01\right)$ but not placental weight $(p>0.05)$; $30^{\circ}$ rotational estimation demonstrated the strongest biological correlation $\left(R_{s}=0.40, p=0.0004\right)$. Intra- and interobserver placental size measurements intraclass correlation coefficients were suboptimal $(0.59-0.70$ and $0.10-0.58$ respectively).

Discussion: We have demonstrated that it is possible to obtain information about the size of the third trimester placenta in utero using 2D and 3D ultrasound. However it is essential that the reliability (particularly interobserver reliability) of these estimates is improved prior to prospective studies to determine their predictive value.
\end{abstract}

๑) 2016 Published by Elsevier Ltd.

\section{Introduction}

Smaller ex vivo placental size, with or without increase in fetoplacental ratio (FPR), is observed in pregnancies ending in stillbirth [1,2], fetal growth restriction (FGR) $[3,4]$ and reduced fetal movement pregnancies with adverse outcome [5] compared to normal outcome pregnancies. Sonographically detectable placental growth restriction precedes FGR by several weeks [6], thus assessment of in utero placental size, alone or in relation to fetal size, may improve prediction of adverse pregnancy outcome.

Two-dimensional (2D) ultrasound measures of placental

\footnotetext{
* Corresponding author. Clinical Research Fellow, Maternal and Fetal Health Research Centre, University of Manchester, 5th Floor Research, St. Mary's Hospital, Oxford Road, Manchester, M13 9WL, United Kingdom.

E-mail address: lucy.higgins@doctors.org.uk (L.E. Higgins).
}

diameter and thickness have been used as indicators of high-risk pregnancies [7-11]. First trimester sonographic placental volume (PV) using the three-dimensional (3D) ultrasound technique Virtual Organ Computer Aided anaLysis (VOCAL) is smaller in pregnancies ending in delivery of small for gestational age (SGA) infants $[12,13]$ early-onset FGR and hypertensive disorders [14-16]. In contrast late-onset FGR and preeclampsia pregnancies failed to show an appreciable significant difference in first trimester VOCAL PV [16-18]. However, no studies have examined the accuracy of these techniques, or whether there is any meaningful correlation between in utero sonographic placental biometry measurements and direct measurements of ex vivo placental size after delivery.

In contrast, a 2D PV technique has been correlated to placental weight (PW) [19]. It is not known whether PW and PV are consistently related; therefore this correlation may prove inappropriate. In the second trimester this technique demonstrates reasonable 
specificity (91\%) but low sensitivity (19\%) for SGA birth [20]; pregnancies with $\mathrm{PV}<25$ th centile are twice as likely to experience adverse outcome [21].

This study investigated the relationship between placental volume and weight, and tested the hypothesis that placental biometry and volume can be accurately and reproducibly measured in utero in third trimester pregnancies. Here we define accuracy as the ability of in vivo measurement to relate to ex vivo measurement and reproducibility to describe the variability of the measurement. Biological relevance (relationship of the measure to an outcome of interest) is not tested in this study.

\section{Materials and methods}

Women with non-anomalous singleton pregnancies of $\geq 28$ weeks gestation undergoing third trimester ultrasound examination (for assessment of reduced fetal movements, suspected or confirmed FGR or confirmation of fetal presentation) gave written informed consent to participate in the ethically approved study (11/ NW/0650, Greater Manchester North West Research Ethics Committee) by undergoing additional ultrasound measurements and placental donation.

\subsection{Sonographic assessment of placental size and shape}

Ultrasound examinations were conducted by a single sonographer (LH) using a Voluson E6 with a RA4B 4-8 Hz curvilinear probe (GE Healthcare). Fetal weight was estimated (EFW) according to the Hadlock C formula [22]. Using 2D ultrasound the placental was located and its longest plane identified. The ultrasound probe was angulated to include as much placenta as possible and to minimise acoustic shadowing from the fetus. A 2D image and 3D volume $\left(85^{\circ}\right.$ sweep) of the placenta were captured in this plane. The probe was rotated $90^{\circ}$, the longest perpendicular plane identified and a further 2D image was captured. This procedure was repeated three times. 2D images were analysed in real time, 3D images were analysed offline using 4Dview version 5.0 (GE Healthcare) ultrasound image analysis software. Throughout the manuscript, the prefix "est" refers to an in utero estimate of a particular aspect of placental size. Accuracy refers to the existence of a significant statistical correlation between estimated and true measurements. Biological relevance (relationship of the measure to an outcome of interest) is not tested in this study.

\subsection{Modelling of placental shape and tissue density}

Placentas were trimmed of their extra-placental membranes and umbilical cord. The PW and PV (measured by volume displacement [23]) were recorded and the placentas were photographed, chorionic plate facing upward alongside a scale bar. Placental depth (D) was measured directly at the apparent deepest point of the placenta. Using Image ProPlus version 6.0 (Media Cybernetics UK, Marlow, UK) placental photographs were analysed to quantify placental length ( $\mathrm{L}$; longest diameter of the placenta), width (W; longest diameter perpendicular to the placental length) and average diameter $(A)$. These measurements were incorporated into formulae for the volume of an ellipse (4/ $3 \pi \times 0.5 \mathrm{~L} \times 0.5 \mathrm{~W} \times 0.5 \mathrm{D})$, elliptical cylinder $(\pi \times 0.5 \mathrm{~L} \times 0.5 \mathrm{~W} \times \mathrm{D})$ and circular cylinder $\left(\pi \times(0.5 \mathrm{~A})^{2} \times \mathrm{D}\right)$. The modelled ex vivo PV determined by each formula was then correlated to true ex vivo PV. The model that best approximated true PV was carried forward into subsequent analyses. Tissue density was expressed as the ratio of PW to PV.

\subsection{Correlation of sonographic and true placental biometry, volume, weight and fetoplacental ratio}

Subgroup analysis of those placentas delivered within seven days of ultrasound examination was performed to test the accuracy of sonographic placental measurements. Systematic and random errors were calculated for the most accurate method of estimating each placental size measure (as determined by the highest correlation coefficient of statistically significant measurement methods).

\subsubsection{Placental biometry}

${ }^{\text {est }} \mathrm{L}$ (from images of the longest plane of the placenta) and ${ }^{\text {est }} \mathrm{W}$ (from images of the longest perpendicular plane of the placenta) were estimated in three ways; (i) a straight line (or two straight lines meeting at the angle of the placenta if the placenta was particularly curved) through the placenta from tip to tip (Fig. 1A) [24], (ii) a curvilinear line along the maternoplacental interface (Fig. 1B) [25], and (iii) a curvilinear line through the middle of the placenta (Fig. 1C). For 2D measurements, if the placental length or width could not be fully captured in any single image, real-time extrapolation based on the data ascertained from movement of the probe along the placenta was permitted. ${ }^{e s t} \mathrm{D}$ was estimated at the visibly deepest point of the placenta, perpendicular to its plane

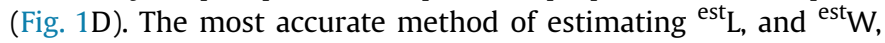
were carried forward into further analyses.

\subsubsection{Placental volume and weight}

${ }^{\text {est }} \mathrm{PV}$ was then measured in four ways. Firstly it was calculated according to the most appropriate geometric formula (as assessed above) using $2 \mathrm{D}{ }^{\text {est }} \mathrm{L}$, ${ }^{\text {est }} \mathrm{W}$ and ${ }^{\text {est }} \mathrm{D}$ (Fig. 2A). Next the placental arc was measured as previously published [19] (Fig. 2B) and the ${ }^{\text {est }} \mathrm{PV}$ calculated from the concave convex shell formula $(1 / 4 \pi(\mathrm{T} /$ 6) $\left.\times\left[4 \mathrm{H}(\mathrm{B}-\mathrm{T})+\mathrm{B}(\mathrm{B}-4 \mathrm{~T})+4 \mathrm{~T}^{2}\right]\right)$ where $\mathrm{B}$ refers to the tip-to-tip distance across the base of the placental arc, $H$ to the maximal height of the arc and $\mathrm{T}$ to the thickness of placental tissue at the maximal height of the arc. Finally, 3D volumes were analysed; volumes were rejected and reacquired if the majority of the placenta could not be captured in a single sweep. The placental outline was traced at both $30^{\circ}\left(\operatorname{VOCAL} 30^{\circ}\right)$ and $15^{\circ}\left(\operatorname{VOCAL~} 15^{\circ}\right)$ rotation angles (Fig. 2C) as previously described [26-28], and at "slicing" intervals of $10 \mathrm{~mm}$ (MP10) and $5 \mathrm{~mm}$ (MP5) (Fig. 2D) in a modification of the multiplanar technique described by Cheong et al. in the first trimester [29], and Hafner et al. in the second

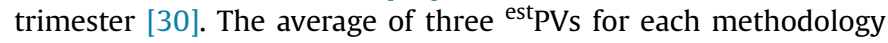
was taken per placenta to minimise random error. PW was estimated ( ${ }^{\text {est }} \mathrm{PW}$ ) by multiplication of ${ }^{\text {est }} \mathrm{PV}$ by placental tissue density (as assessed above). The most accurate ${ }^{\text {est }} \mathrm{PV}$ and ${ }^{\text {est }} \mathrm{PW}$ techniques were taken forward into further analyses.

\subsubsection{Fetoplacental ratio}

FPR was assessed to examine placental efficiency, dividing EFW by ${ }^{\text {est }} \mathrm{PV}$ and ${ }^{\text {est }} \mathrm{PW}$ to respectively generate fetoplacental volume and weight ratios ( ${ }^{\text {est }} \mathrm{FPRv}$ and ${ }^{\text {est } \mathrm{FPRw} \text { ). }}$

\subsection{Assessment of sonographic reliability}

Throughout the study data was collected regarding reproducibility, by analysis of intra- and inter-observer reliability of placental sonographic measures in a series of scans conducted in triplicate $(\mathrm{N}=46)$ by two sonographers ( $\mathrm{LH}$ and $\mathrm{LS})$ following the same methodologies described above. Three measurement sets were obtained $\left(\mathrm{LH}_{1}, \mathrm{LS}, \mathrm{LH}_{2}\right)$ from each participant, with each sonographer blinded to the values obtained in each previous assessment. Intra-observer reliability was assessed by comparison of $\mathrm{LH}_{1}$ and $\mathrm{LH}_{2}$ values, whilst inter-observer reliability was assessed by 

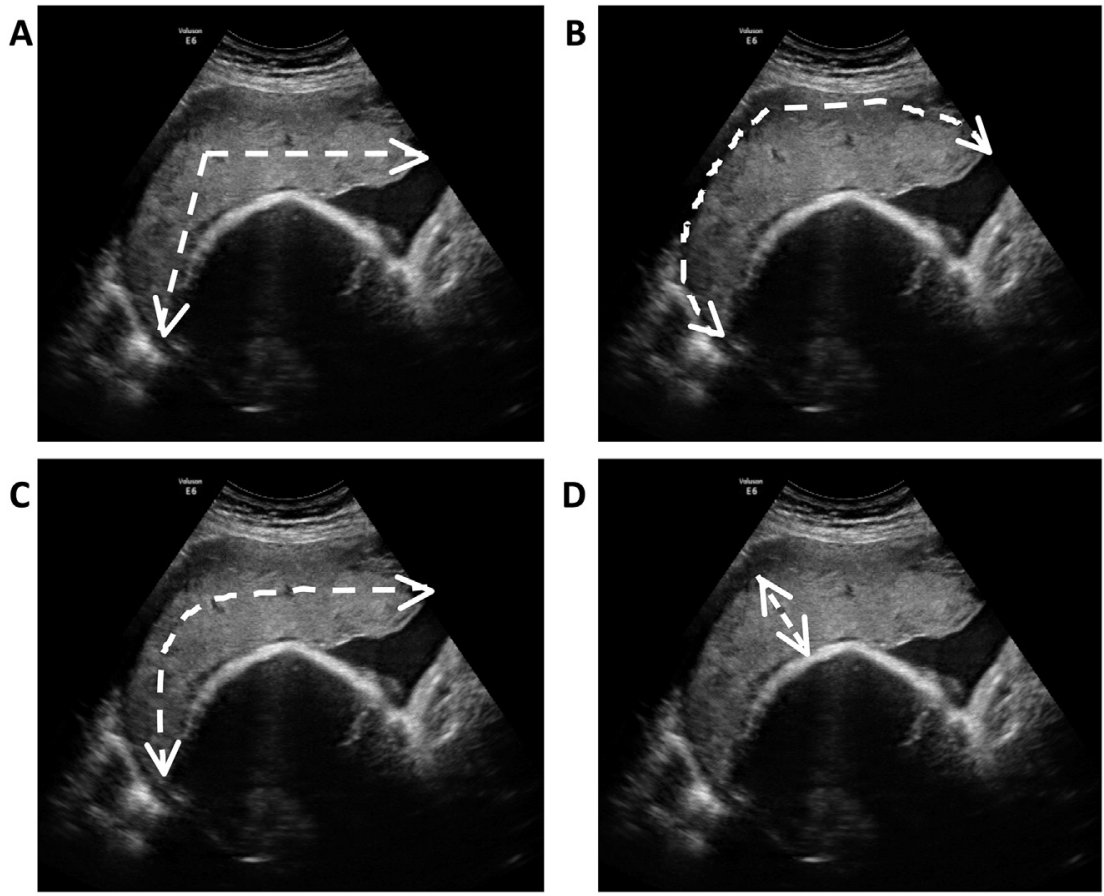

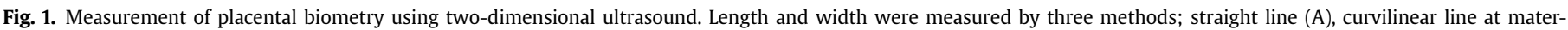

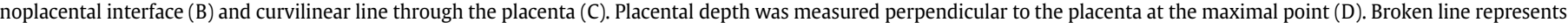
line of measurement.
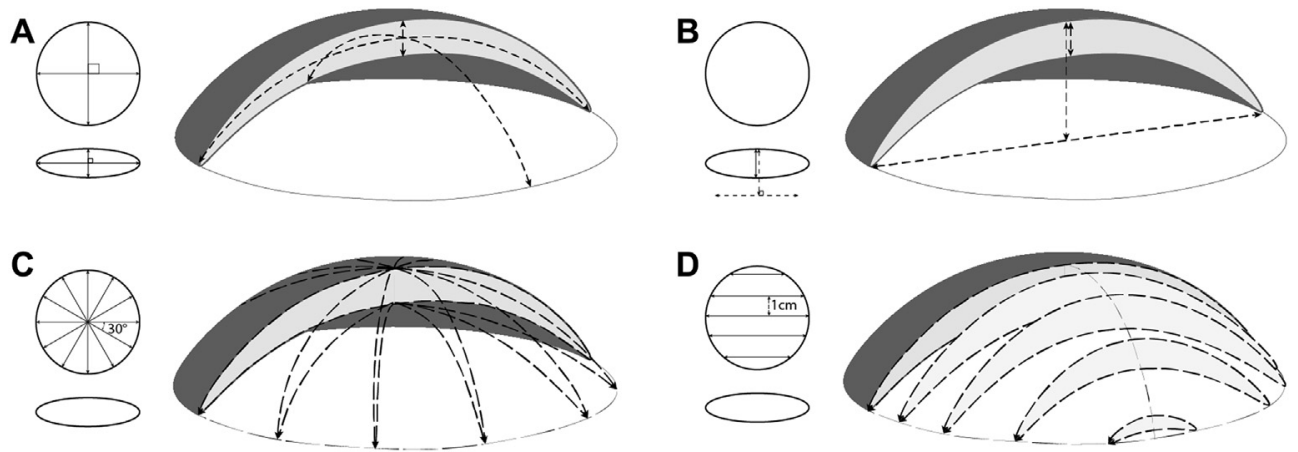

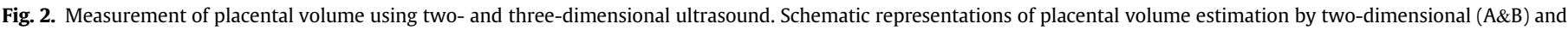

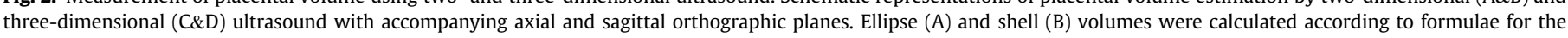

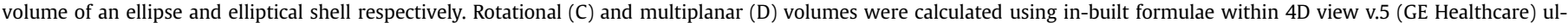
trasound image analysis software after tracing the placental outline at pre-specified rotation or slicing intervals. Broken line represents line of measurement.

comparison of $\mathrm{LH}_{1}$ and LS values [31].

\subsection{Statistical analysis}

The study cohort was divided into subgroups by scan to delivery interval using a cut off of seven days. Subgroups were compared to assess for selection bias; data were compared by Mann-Whitney $U$ Test (for continuous data) and Chi squared test (for categorical data). Sonographic accuracy was assessed in women giving birth within 7 days by Spearman Rank Correlation. The strength of that association was determined by the highest $R_{S}$ value of each set of measurements; where equal, the most accurate method of estimation was determined to be the one with smallest systematic error (Systematic error: (predicted - true)/true. Random error: standard deviation of systematic errors). The most accurate method of estimating each measurement was taken forward into subsequent analyses. Reliability (intra- and inter-observer) was assessed as the coefficient of variance (CoV; standard deviation of measures/average of measures), intra-class correlation coefficient (ICC $(3,1)$ ), bias and $95 \%$ limits of agreement. An ICC $>0.75$ was considered good [32]. Statistical analysis was carried out using Prism 6 for Mac OS X (Graphpad Software Inc., San Diego, USA) and statistical significance was determined by a $\mathrm{p}$ value $<0.05$.

Based on an expected correlation of 0.68 between ${ }^{\text {est }} \mathrm{PV}$ and PV in term pregnancies and an up to $37.5 \%$ failure to obtain third trimester measurements [19] a minimum of 22 placentas would be required to detect a significant correlation of similar magnitude with power of $80 \%$ at the level of $p<0.05$. Given the local proportion of pregnancies delivering within seven days of assessment for reduced fetal movements (32.6\%, unpublished data) and a $10 \%$ loss to follow up rate, we estimated that at least 120 participants would need to be recruited to obtain sufficient matched in vivo and 
ex vivo datasets.

\section{Results}

\subsection{Recruitment and assessment of biological correlation}

Placentas from 129 participants were received; these pregnancies formed the whole study cohort. Table 1 summarises their maternal and pregnancy characteristics. Eighty-seven (67.4\%) pregnancies delivered within seven days of ultrasound examination; in vivo and ex vivo measurements were compared in this group. One or more 2D placental measurements were not obtained in two cases (2.3\%) and 3D volumes were deemed inadequate due to excessive movement artefact or inadequate visualisation in four cases (4.6\%). EFW was highly significantly correlated with true birth weight $\left(\mathrm{R}_{\mathrm{s}}=0.77, \mathrm{p}<0.0001\right)$ indicating that the sonographic accuracy in general was good.

\subsection{Ex vivo placental volume modelling and tissue density}

Each shape approximation modelled PV with highly significant relationship to the true PV $\left(R_{S}=0.74, p<0.0001\right.$ for each). However, systematic bias differed significantly; ellipse (6.4\% underestimation), elliptical cylinder (42.2\% overestimation) and circular cylinder (182.8\% overestimation). PW and PV were highly significantly correlated $\left(\mathrm{R}_{\mathrm{S}}=0.96, \mathrm{p}<0.0001\right)$ with a placental tissue density of $1.05 \mathrm{~g} / \mathrm{cm}^{3}\left(1.03-1.09 \mathrm{~g} / \mathrm{cm}^{3}\right)$.

\subsection{Correlation of sonographic estimated placental biometry,} volume, weight and fetoplacental ratio

\subsubsection{Placental biometry}

Table 2 summarises the performance of each described method of measuring 2D placental biometry. Statistically significant relationships were observed between ${ }^{\mathrm{est}} \mathrm{L}$ and $\mathrm{L}$ using only method 3 , whilst for ${ }^{\text {est }} \mathrm{W}$ both methods 1 and 3 each correlated with $\mathrm{W}$ with statistical significance; once more method 3 performed best. ${ }^{\text {est }} \mathrm{D}$ was significantly related to the $\mathrm{D}$. Systematic and random errors for
Table 2

Comparison of sonographically estimated placental biometry, volume and weight to ex vivo directly measured placental size.

\begin{tabular}{llll}
\hline Measurement & Method & $\mathrm{R}_{\mathrm{s}}$ & $\mathrm{p}$ \\
\hline Length & 1 & 0.16 & 0.13 \\
& 2 & 0.088 & 0.43 \\
Width & 3 & 0.24 & 0.031 \\
& 1 & 0.26 & 0.17 \\
Depth & 2 & 0.17 & 0.13 \\
Volume & 3 & 0.27 & 0.013 \\
& Maximum & 0.31 & 0.0056 \\
& Ellipse & 0.35 & 0.0017 \\
& Shell & 0.32 & 0.0039 \\
& VOCAL 30 & 0.40 & 0.0004 \\
Weight & VOCAL 15 & 0.37 & 0.0009 \\
& MP 10 mm & 0.36 & 0.0012 \\
& MP 5 mm & 0.38 & 0.0007 \\
& Ellipse & -0.17 & 0.13 \\
& Shell & -0.19 & 0.087 \\
& VOCAL 30 & -0.20 & 0.081 \\
& VOCAL 15 & -0.20 & 0.073 \\
& MP 10 mm & -0.20 & 0.082 \\
& MP 5 mm & -0.16 & 0.15 \\
\hline
\end{tabular}

Placental length and perpendicular width were sonographically estimated by three methods 1 ) straight line(s), and curvilinear lines along 2) maternoplacental interface and 3 ) the centre of the placenta. Placental depth was determined as the thickest measurement perpendicular placental length. Elliptical volume was estimated from two-dimensional (2D) sonographic estimates of length (L), width (W) and depth (D). Shell volume was estimated from 2D measurements of the placental arc. Threedimensional (3D) rotational (VOCAL, rotational angle) and multiplanar (MP, slicing interval) measurement techniques. $\mathrm{N}=87$ (deliveries within 7 days of placental biometry scan), Spearman Rank Correlation.

each measurement were significant, particularly for ${ }^{\text {est }} \mathrm{D}$ (Systematic error: ${ }^{\text {est }} \mathrm{L}=-14.76 \%$, ${ }^{\text {est }} \mathrm{W}=-13.35 \%$, ${ }^{\text {est }} \mathrm{D}=97.83 \%$. Random error: ${ }^{\text {est }} \mathrm{L}=17.14 \%$, ${ }^{\text {est }} \mathrm{W}=18.32 \%$, ${ }^{\text {est }} \mathrm{D}=49.66 \%$ respectively).

\subsubsection{Placental volume and weight}

Table 2 also summarises the performance of each method of estimating PV. ${ }^{\text {est }} \mathrm{PV}$ by the 2D elliptical model (using ${ }^{\text {est }} \mathrm{L}$ and ${ }^{\text {est }} \mathrm{W}$ by method 3 above) was more accurate than the previously published shell method. All 3D ${ }^{\text {est }}$ PV methods demonstrated higher

Table 1

The placental ultrasound study cohort.

\begin{tabular}{|c|c|c|c|c|}
\hline \multirow[t]{2}{*}{ Scan to delivery interval (days) } & \multirow{2}{*}{$\begin{array}{l}\text { Whole cohort } \\
\text { Any }\end{array}$} & \multicolumn{2}{|l|}{ Subgroup-analysis } & \multirow[t]{3}{*}{$\mathrm{p}$} \\
\hline & & $\leq 7$ & $>7$ & \\
\hline $\mathrm{N}$ & 129 & 87 & 42 & \\
\hline \multicolumn{5}{|l|}{ Maternal Characteristics } \\
\hline Age (years) & $29.2(25.0-33.1)$ & $30.8(26.0-33.5)$ & $29.0(23.6-33.2)$ & 0.31 \\
\hline Ethnicity: & & & & 0.34 \\
\hline Caucasian & $93(72.1 \%)$ & $63(72.4 \%)$ & $30(71.4 \%)$ & \\
\hline Asian & $17(13.2 \%)$ & $11(12.6 \%)$ & $6(14.2 \%)$ & \\
\hline Black & $9(7.0 \%)$ & $8(9.2 \%)$ & $1(2.4 \%)$ & \\
\hline Other & $10(7.8 \%)$ & $5(5.7 \%)$ & $5(11.9 \%)$ & \\
\hline BMI $\left(\mathrm{kg} / \mathrm{m}^{2}\right)$ & $26.0(23.1-30.2)$ & $25.5(23.1-29.5)$ & $28.1(22.9-31.6)$ & 0.30 \\
\hline Parity (number) & $0(0-1)$ & $1(0-1)$ & $0(0-1)$ & 0.12 \\
\hline \multicolumn{5}{|l|}{ Pregnancy Characteristics } \\
\hline Gestation at Scan (weeks ${ }^{+ \text {days }}$ ) & $38^{+6}\left(37^{+2}-40^{+1}\right)$ & $39^{+0}\left(38^{+2}-40^{+3}\right)$ & $36^{+0}\left(32^{+3}-38^{+2}\right)$ & \\
\hline Placental site: & & & & $<0.0001$ \\
\hline Anterior & $39(30.2 \%)$ & $28(32.2 \%)$ & $11(26.1 \%)$ & \\
\hline Lateral & $45(34.9 \%)$ & $40(46.0 \%)$ & $5(11.9 \%)$ & \\
\hline Posterior & $15(11.6 \%)$ & $9(10.3 \%)$ & $6(14.3 \%)$ & \\
\hline Fundal & $12(9.3 \%)$ & $7(8.0 \%)$ & $5(11.9 \%)$ & \\
\hline Not defined & $18(14.0 \%)$ & $3(3.4 \%)$ & $15(35.7 \%)$ & \\
\hline Scan to delivery interval (days) & $3(1-7)$ & $2(0-4)$ & $20(12-54)$ & $<0.0001$ \\
\hline Individualised birth weight centile & $36(14.5-61.2)$ & $36(14.3-63.2)$ & $48(15.5-60)$ & 0.56 \\
\hline
\end{tabular}

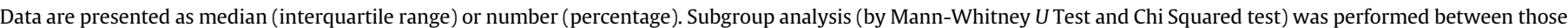

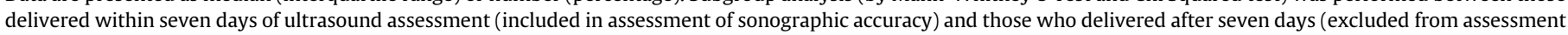
of sonographic accuracy). 
statistical correlation than either $2 \mathrm{D}^{\text {est }} \mathrm{PV}$ method, with VOCAL $30^{\circ}$ performing with the highest statistical significance $\left(R_{S}=0.40\right.$, $\mathrm{p}=0.0004$ ) and demonstrating greater accuracy (particularly at smaller placental volumes). Despite the observed correlation between PW and PV, neither est PV nor ${ }^{\text {est }} \mathrm{PW}$ correlated (by any method) significantly correlated with $\mathrm{PW}(\mathrm{p}>0.05)$. In comparison to the 2D biometric measures, 3D systematic error was improved ( ${ }^{\text {est }} \mathrm{PV}=0.60 \%$, ${ }^{\text {est }} \mathrm{PW}=0.91 \%$ ) but random error was greater ( ${ }^{\text {est }} \mathrm{PV}=35.61 \%$, ${ }^{\text {est }} \mathrm{PW}=34.38 \%$ ).

\subsubsection{Fetoplacental ratio}

As ${ }^{\text {est }} \mathrm{PW}$ failed to correlate with PW, statistical correlation of ${ }^{\text {est }}$ FPRw was not assessed. ${ }^{\text {est }} \mathrm{FPRv}$ by VOCAL $30^{\circ}$ correlated with true FPRv $\left(R_{S}=0.30, p=0.0063\right)$ with systematic error of $16.88 \%$ and random error of $48.46 \%$.

\subsection{Assessment of sonographic reliability}

Table 3 summarises the reliability indices of each placental measurement. For all measures the variability in measurements (intra- and inter-) was suboptimal with no ICC $>0.75$. Interobserver variability exceeded intra-observer variability with Bland Altman plots demonstrating wide limits of agreement for all measures (Fig. 3). The degree of bias was unaffected by placental size $(\mathrm{p}>0.05)$.

\section{Discussion}

This study has established that placental biometry and volume can be estimated with statistical correlation to true placental size using 2D and 3D ultrasound in third trimester pregnancies. Such measurements are clinically desirable as reduced placental size is related to FGR and stillbirth [2,3]. This study suggests that small placental size can be identified by placental ultrasound in the third trimester of pregnancy but did not attempt to assess whether this assisted prediction of pregnancy outcome.

Ex vivo modelling identified the ellipse as the appropriate geometric volume for PV estimation, explaining why the 2D ellipse has a higher statistical correlation than the previously described shell

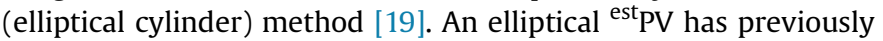
been applied in the first trimester of pregnancy [25] but utilised ${ }^{\text {est }} \mathrm{L}$ and ${ }^{\text {est }} \mathrm{W}$ derived by method 2, shown here to be less correlated to true $\mathrm{L}$ and $\mathrm{W}$ than method 3 in the third trimester. Conversely, the shell ${ }^{\text {est }} \mathrm{PV}$ method was previously correlated to PW in a much smaller cohort ( 38 participants, with $23.7 \%$ overall failure rate) [19] compared to our validation cohort of 87 pregnancies (with $2.3-4.6 \%$ failure rate) in which we were unable to replicate the previously reported correlation between shell ${ }^{\text {est }} \mathrm{PV}$ and $\mathrm{PW}$, despite establishing a constant relationship between PW and PV, with a tissue density close to 1.0 (as in liver [33]). Indeed, no

Table 3

Reliability of third trimester placental size assessment.

\begin{tabular}{llclc}
\hline Measure & & $\operatorname{CoV}(\%)$ & ICC & 0070 \\
\hline Length & Intra & 8.3 & 0.68 & $<0.0001$ \\
& Inter & 14.0 & 0.096 & 0.39 \\
Width & Intra & 9.5 & 0.70 & $<0.0001$ \\
& Inter & 10.8 & 0.37 & 0.098 \\
Depth & Intra & 12.4 & 0.59 & 0.0030 \\
\multirow{2}{*}{ Volume } & Inter & 13.0 & 0.58 & 0.0090 \\
& Intra & 14.4 & 0.66 & 0.0010 \\
& Inter & 26.2 & 0.54 & 0.011 \\
\hline
\end{tabular}

Intra- and inter-observer reliability was assessed in a series scans $(\mathrm{N}=46)$ by two observers. Variability between observations is displayed as the coefficient of variance $(\mathrm{CoV})$ and intraclass correlation coefficient (ICC). method of ${ }^{\text {est }} \mathrm{PW}$ or ${ }^{\text {est }} \mathrm{PV}$ demonstrated statistical correlation with PW, although several approached statistical significance. This may be a result of the relatively small sample size studied and suboptimal reproducibility (see below), however we believe this currently prohibits use of PW to validate ${ }^{\mathrm{est}} \mathrm{PV}$, and prevents generation of a dimensionless third trimester placental quotient (FPRw) [34].

While estimated and true placental size values are correlated, they are not equal with ${ }^{\text {est }} \mathrm{L}$, ${ }^{\text {est }} \mathrm{W}$, and $3 \mathrm{D}{ }^{\text {est }} \mathrm{PV}$ being smaller and ${ }^{\text {est }} \mathrm{D}$ and $2 \mathrm{D}{ }^{\text {est }} \mathrm{PV}$ larger than their ex vivo correlates. ${ }^{\text {est }} \mathrm{D}$ and ${ }^{\text {est }} \mathrm{PV}$ may be inflated by placental blood [35] whilst the other measures may be reduced by "missed" placental tissue. Furthermore the strength of the relationship is lower here than predicted from previous studies [19]. This implies that sonographic placental measurements should be compared against in vivo, rather than ex vivo reference curves.

Our study further suggests that development of clinically useful in vivo reference curves may be impaired by the intra- and interobserver variability in these measures. The effect of the operator "learning curve" on reliability was not examined, however performance may improve with experience, particularly in relation to extrapolation if contemporaneous feedback was provided regarding accuracy of placental measurement. $2 \mathrm{D}$ ultrasound reliability data are limited; a singular study of second trimester placental biometry reports very high reliability (ICCs $\geq 0.92$ ) [36]. At such early gestation the majority of placentas should be fully visualised in a single image, removing the need for real time extrapolation. Extrapolation is felt likely to contribute to the lower reliability estimates for the $2 \mathrm{D}$ placental estimates in this third trimester study. However the specific contribution of extrapolation variability cannot be ascertained in the current study.

A significant contribution of "missed tissue" to the suboptimal reliability of third trimester measures may also be inferred as, using the same technique, (and without extrapolation) other researchers have reported much higher intra- and inter-observer ICCs $\geq 0.88$ using VOCAL ${ }^{\text {est }} \mathrm{PV}$ in the first and second trimesters [29,30,37], and between 12 and 40 weeks gestation (majority of measurements obtained $<28$ weeks gestation) [26] than those demonstrated in this third trimester study. However, other researchers employing robust methodologies have also demonstrated similar reliability (ICC 0.59 with wide limits of agreement) using this technique even in the first trimester [38].

It is not yet known whether differences in the size of term pregnancy placentas that exceed full visualisation in a single image are clinically relevant. Indeed depending on factors such as placental site, maternal habitus, fetal size and gestation the impact of excluding "missed" placental tissue in the assessment of placental size might have a disproportionate effect on the usefulness of a test of placental size if real-time extrapolation was not performed. Whether the reliability demonstrated in our study (ICC $<0.75$ ) is sufficient to detect relatively subtle differences (e.g. $<3 \mathrm{~cm}$ difference in placental length and width [5]) in placental size remains to be seen, although both Pomorski et al. [39] and Artunc Ulkumen et al. [28] were able to detect a $92 \mathrm{~cm}^{3}$ reduction in VOCAL ${ }^{\text {est }}$ PV between third trimester FGR and control pregnancies. This should be the subject of future work in this area, alongside comparative assessment of the clinical utility of these measures against other assessments of in utero placental structure and function including umbilical and uterine artery Doppler impedance and placental hormonal assessment.

The strength of this study is the like-for-like correlation of placental size estimation techniques to their true biological correlates with a short scan-to-delivery interval. This resulted in development of placental measurements that may be tested prospectively to subsequently determine relation to pregnancy 


\section{Intra-Observer}

\section{A}

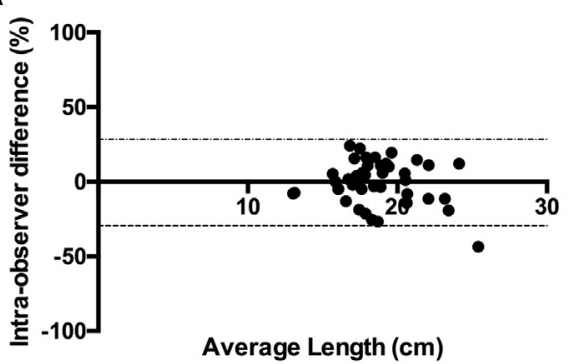

\section{B}

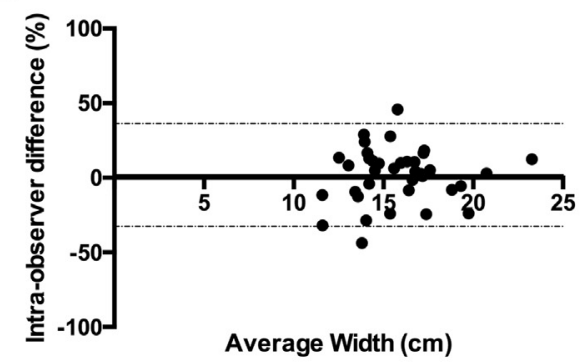

C

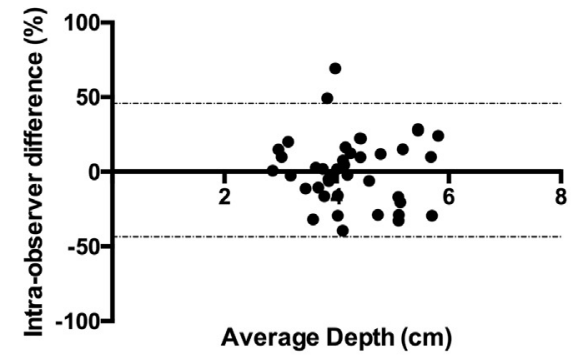

D

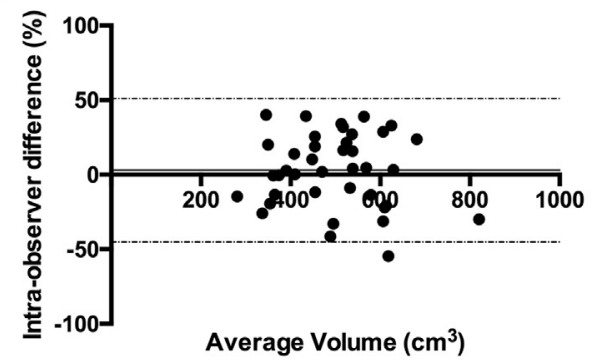

Inter-Observer
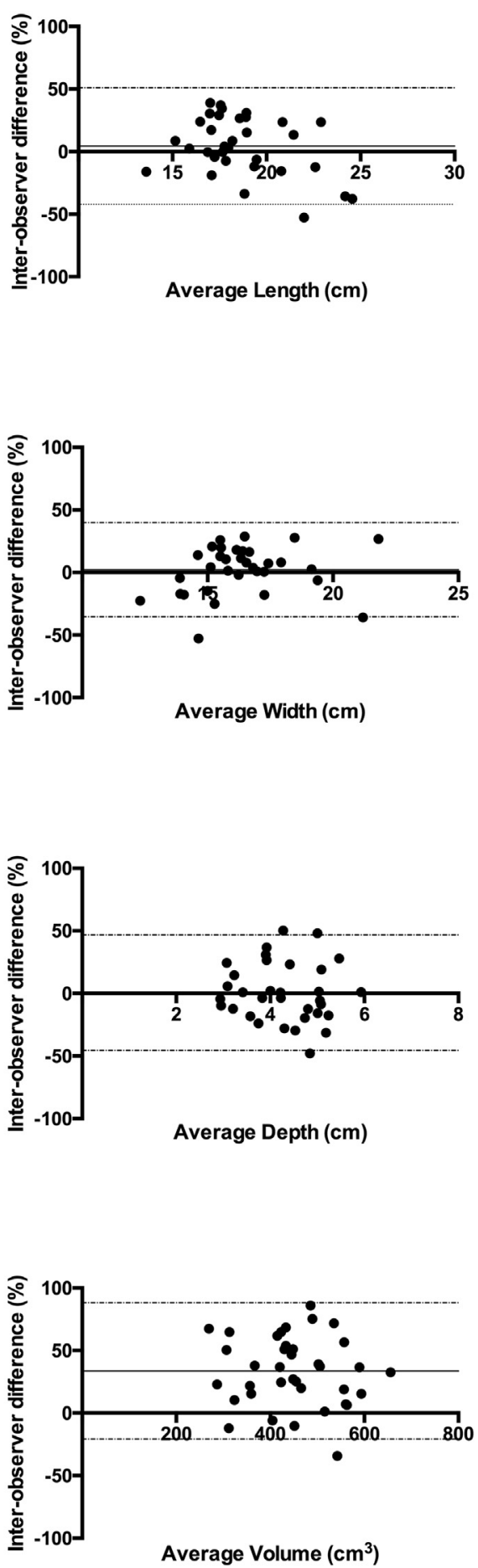

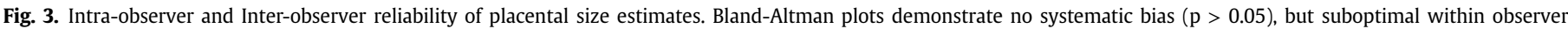

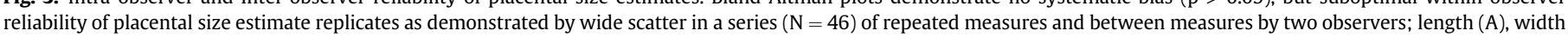

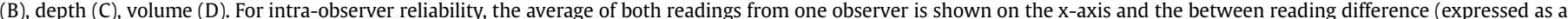

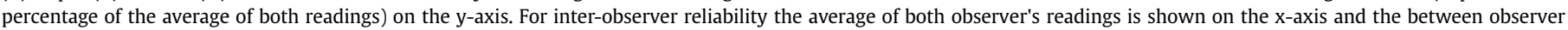

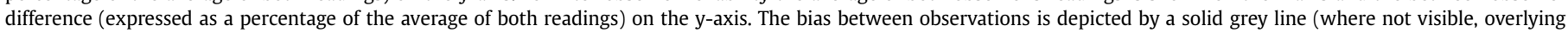
$\mathrm{y}=0$ ); the $95 \%$ limits of agreement are depicted by a broken line.

outcome in the future. The study assessed placentas in advanced gestation, irrespective of placental site, maternal body mass index and fetal size, in an ethnically diverse cohort, making the study findings generally applicable in a wide range of health care settings.
There is little reason to suspect that these methodologies would not remain valid at earlier gestations.

The primary limitations of the study are that each method of placental size estimation demonstrated relatively poor intra- and 
inter-observer reliability, particularly in ${ }^{\mathrm{est}} \mathrm{L}$ measurement. This implies that significant refinement of the technique is required prior to clinical application. Further investigation of the contribution of extrapolation to both reliability, statistical correlation and subsequently to pregnancy outcome prediction is essential before this aspect of the technique is accepted or rejected. Other potential limitations of the study include the cross-sectional nature, sample size and high-risk population, which prevent generation of centile charts.

\section{Conclusions}

With increasing interest in antenatal placental assessment to identify potentially compromised pregnancies, this study provides evidence that placental size can be estimated in the third trimester with statistical correlation to its true size. The biological relevance of these results remains untested, but may be limited by suboptimal reliability of these measurements. Thus, reliability of in utero placental size estimates needs to be improved before prospective studies to determine if placental size assessment is useful in prediction of pregnancy outcome.

\section{Statement of author contributions}

The project was conceived by EDJ, AEPH, CPS and LH, and methodologies planned by LH with expert supervision from EDJ (sonography). LS performed ultrasound scans for analysis of interobserver reliability. LH performed all other ultrasound scans and all other analyses. Statistical analysis and manuscript preparation was performed by LH. All authors were involved in writing the paper and had final approval of the submitted and published versions.

\section{Acknowledgements}

The authors would like to thank the women who participated in this study and the midwives at St Mary's Hospital, Manchester for their assistance in participant recruitment and placental collection after birth. Dr L Higgins is supported by an Action Medical Research Training Fellowship (GN2136) and a Manchester NIHR Biomedical Research Centre fellowship. The study was also supported by Tommy's - the Baby Charity.

\section{References}

[1] A.E. Heazell, E.A. Martindale, Can post-mortem examination of the placenta help determine the cause of stillbirth? J. Obstet. Gynaecol. 29 (3) (2009) 225-228.

[2] S. Worton, A.E.P. Heazell, Decreased placental weight centile and increased birthweight: placental weight ratios in stillbirth suggests placental insufficiency even in stillbirths of "unknown" cause, Placenta 35 (9) (2014) A15-a16.

[3] S. Biswas, S.K. Ghosh, Gross morphological changes of placentas associated with intrauterine growth restriction of fetuses: a case control study, Early Hum. Dev. 84 (6) (2008) 357-362.

[4] R.L. Balihallimath, V.S. Shirol, A.M. Gan, N.K. Tyagi, M.R. Bandankar, Placental morphometry determines the birth weight, J. Clin. Diagn. Res. 7 (11) (2013) $2428-2431$.

[5] L.E. Higgins, N. Rey de Castro, N. Addo, M. Wareing, S.L. Greenwood, R.L. Jones, C.P. Sibley, E.D. Johnstone, A.E. Heazell, Placental features of late-onset adverse pregnancy outcome, PLoS One 10 (6) (2015) e0129117.

[6] H. Wolf, H. Oosting, P.E. Treffers, A longitudinal study of the relationship between placental and fetal growth as measured by ultrasonography, Am. J. Obstet. Gynecol. 161 (5) (1989) 1140-1145.

[7] S. Viero, V. Chaddha, F. Alkazaleh, M.J. Simchen, A. Malik, E. Kelly, R. Windrim, J.C. Kingdom, Prognostic value of placental ultrasound in pregnancies complicated by absent end-diastolic flow velocity in the umbilical arteries, Placenta 25 (8-9) (2004) 735-741.

[8] M. Toal, C. Chan, S. Fallah, F. Alkazaleh, V. Chaddha, R.C. Windrim, J.C. Kingdom, Usefulness of a placental profile in high-risk pregnancies, Am. J. Obstet. Gynecol. 196 (4) (2007) 363 e1-7.

[9] M. Toal, V. Chaddha, R. Windrim, J. Kingdom, Ultrasound detection of placental insufficiency in women with elevated second trimester serum alpha-fetoprotein or human chorionic gonadotropin, J. Obstet. Gynaecol. Can. 30 (3) (2008) 198-206.

[10] M. Toal, S. Keating, G. Machin, J. Dodd, S.L. Adamson, R.C. Windrim, J.C. Kingdom, Determinants of adverse perinatal outcome in high-risk women with abnormal uterine artery Doppler images, Am. J. Obstet. Gynecol. 198 (3) (2008) 330 e1-7.

[11] L.K. Proctor, M. Toal, S. Keating, D. Chitayat, N. Okun, R.C. Windrim, G.C. Smith, J.C. Kingdom, Placental size and the prediction of severe early-onset intrauterine growth restriction in women with low pregnancy-associated plasma protein-A, Ultrasound Obstet. Gynecol. 34 (3) (2009) 274-282.

[12] L.W. Law, T.Y. Leung, D.S. Sahota, L.W. Chan, T.Y. Fung, T.K. Lau, Which ultrasound or biochemical markers are independent predictors of small-forgestational age? Ultrasound Obstet. Gynecol. 34 (3) (2009) 283-287.

[13] S.L. Collins, G.N. Stevenson, J.A. Noble, L. Impey, Rapid calculation of standardized placental volume at 11 to 13 weeks and the prediction of small for gestational age babies, Ultrasound Med. Biol. 39 (2) (2013) 253-260.

[14] G. Rizzo, A. Capponi, O. Cavicchioni, M. Vendola, D. Arduini, First trimester uterine Doppler and three-dimensional ultrasound placental volume calculation in predicting pre-eclampsia, Eur. J. Obstet. Gynecol. Reprod. Biol. 138 (2) (2008) 147-151.

[15] N. Bozkurt, A. Basgul Yigiter, H. Gokaslan, Z.N. Kavak, Correlations of fetalmaternal outcomes and first trimester 3-D placental volume/3-D power Doppler calculations, Clin. Exp. Obstet. Gynecol. 37 (1) (2010) 26-28.

[16] T. Arakaki, J. Hasegawa, M. Nakamura, S. Hamada, M. Mishina, H. Takita, K. Ichizuka, A. Sekizawa, Prediction of early and late onset pregnancy induced hypertension using the three-dimensional ultrasound placental volume and uterine artery Doppler findings, Ultrasound Obstet. Gynecol. 45 (5) (2015) 539-543.

[17] G. Rizzo, A. Capponi, M.E. Pietrolucci, A. Capece, D. Arduini, First-trimester placental volume and vascularization measured by 3-dimensional power Doppler sonography in pregnancies with low serum pregnancy-associated plasma protein a levels, J. Ultrasound Med. 28 (12) (2009) 1615-1622.

[18] M. Odeh, E. Ophir, O. Maximovsky, V. Grinin, J. Bornstein, Placental volume and three-dimensional power Doppler analysis in prediction of pre-eclampsia and small for gestational age between week 11 and 13 weeks and 6 days of gestation, Prenat. Diagn. 31 (4) (2011) 367-371.

[19] H. Azpurua, E.F. Funai, L.M. Coraluzzi, L.F. Doherty, I.E. Sasson, M. Kliman, H.J. Kliman, Determination of placental weight using two-dimensional sonography and volumetric mathematic modeling, Am. J. Perinatol. 27 (2) (2010) 151-155.

[20] A.C. Staff, K. Laine, G. Lahmami, J. Gustafsson, H. Surbehan, M.L. Barbero, H.J. Kliman, Second trimester estimated placental volume (EPV) screening is predictive of SGA and LGA at birth, Placenta 32 (9) (2011). A5:PL3.NI4.

[21] K.S. Laine, A.C. Staff, G. Murzakanova, J. Gustafsson, M.L. Barbero, S. Ye, H.J. Kliman, Second trimester estimated placental volume (EPV) screening is predictive of SGA and LGA newborns and adverse pregnancy outcomes, Ultrasound Obstet.Gynecol. 40 (Suppl. 1) (2012), 55-170.

[22] F.P. Hadlock, R.B. Harrist, R.S. Sharman, R.L. Deter, S.K. Park, Estimation of fetal weight with the use of head, body, and femur measurements-a prospective study, Am. J. Obstet. Gynecol. 151 (3) (1985) 333-337.

[23] W. Scherle, A simple method for volumetry of organs in quantitative stereology, Mikroskopie 26 (1) (1970) 57-60.

[24] P. McGinty, N. Farah, V.O. Dwyer, J. Hogan, A. Reilly, M.J. Turner, B. Stuart, M.M. Kennelly, Ultrasound assessment of placental function: the effectiveness of placental biometry in a low-risk population as a predictor of a small for gestational age neonate, Prenat. Diagn. 32 (7) (2012) 620-626.

[25] S. Suri, S. Muttukrishna, E. Jauniaux, 2D-Ultrasound and endocrinologic evaluation of placentation in early pregnancy and its relationship to fetal birthweight in normal pregnancies and pre-eclampsia, Placenta 34 (9) (2013) $745-750$.

[26] C.F. de Paula, R. Ruano, J.A. Campos, M. Zugaib, Placental volumes measured by 3-dimensional ultrasonography in normal pregnancies from 12 to 40 weeks gestation, J. Ultrasound Med. 27 (11) (2008) 1583-1590.

[27] B. Artunc Ulkumen, H.G. Pala, Y. Uyar, F.M. Koyuncu, Y. Bulbul Baytur, The assessment of placental volume and mean gray value in preeclamptic placentas by using three-dimensional ultrasonography, J. Matern. Fetal Neonatal Med. 28 (9) (2015) 1010-1013.

[28] B. Artunc Ulkumen, H.G. Pala, Y. Uyar, F.M. Koyuncu, Y. Bulbul Baytur, The alteration in placental volume and placental mean grey value in growthrestricted pregnancies assessed by 3D ultrasound (Growth restriction \& 3D ultrasonography), J. Obstet. Gynaecol. 35 (5) (2015) 447-450.

[29] K.B. Cheong, K.Y. Leung, T.K. Li, H.Y. Chan, Y.P. Lee, M.H. Tang, Comparison of inter- and intraobserver agreement and reliability between three different types of placental volume measurement technique (XI VOCAL, VOCAL and multiplanar) and validity in the in-vitro setting, Ultrasound Obstet. Gynecol. 36 (2) (2010) 210-217.

[30] E. Hafner, K. Schuchter, M. van Leeuwen, M. Metzenbauer, B. Dillinger-Paller, K. Philipp, Three-dimensional sonographic volumetry of the placenta and the fetus between weeks 15 and 17 of gestation, Ultrasound Obstet. Gynecol. 18 (2) (2001) 116-120.

[31] J.M. Bland, D.G. Altman, Applying the right statistics: analyses of measurement studies, Ultrasound Obstet. Gynecol. 22 (1) (2003) 85-93.

[32] K.S. Khan, P.F. Chien, Evaluation of a clinical test. I: assessment of reliability, BJOG 108 (6) (2001) 562-567. 
[33] B.A. Overmoyer, C.E. McLaren, G.M. Brittenham, Uniformity of liver density and nonheme (storage) iron distribution, Arch. Pathol. Lab. Med. 111 (6) (1987) 549-554.

[34] S.L. Collins, G.N. Stevenson, J.A. Noble, L. Impey, elsevier trophoblast research award lecture: searching for an early pregnancy 3-D morphometric ultrasound marker to predict fetal growth restriction, Placenta 34 (Suppl) (2013) S85-S89.

[35] S. Porat, B. Fitzgerald, E. Wright, S. Keating, J.C. Kingdom, Placental hyperinflation and the risk of adverse perinatal outcome, Ultrasound Obstet. Gynecol. 42 (3) (2013) 315-321.

[36] N. Milligan, M. Rowden, E. Wright, N. Melamed, Y.M. Lee, R.C. Windrim, J.C. Kingdom, Two-dimensional sonographic assessment of maximum placental length and thickness in the second trimester: a reproducibility study, J. Matern. Fetal Neonatal Med. 28 (14) (2015) 1653-1659.
[37] K. Deurloo, M. Spreeuwenberg, M. Rekoert-Hollander, J. van Vugt, Reproducibility of 3-dimensional sonographic measurements of fetal and placental volume at gestational ages of 11-18 weeks, J. Clin. Ultrasound 35 (3) (2007) $125-132$.

[38] N.W. Jones, N.J. Raine-Fenning, H.A. Mousa, E. Bradley, G.J. Bugg, Evaluating the intra- and interobserver reliability of three-dimensional ultrasound and power Doppler angiography (3D-PDA) for assessment of placental volume and vascularity in the second trimester of pregnancy, Ultrasound Med. Biol. 37 (3) (2011) 376-385.

[39] M. Pomorski, M. Zimmer, J. Florjanski, J. Michniewicz, A. Wiatrowski, T. Fuchs, E. Milnerowicz-Nabzdyk, Comparative analysis of placental vasculature and placental volume in normal and IUGR pregnancies with the use of threedimensional Power Doppler, Arch. Gynecol. Obstet. 285 (2) (2012) 331-337. 